This document is the accepted manuscript version of the following article:

Frank, D. C., Poulter, B., Saurer, M., Esper, J., Huntingford, C., Helle, G., ... Weig1, M. (2015). Water-use efficiency and transpiration across European forests during the Anthropocene. Nature Climate Change, 5(6), 579-583. https://doi.org/10.1038/nclimate2614

\title{
Water-use efficiency and transpiration across European forests during the Anthropocene
}

\author{
D. C. Frank ${ }^{1,2^{*}}$, B. Poulter ${ }^{3,4 *}$, M. Saurer ${ }^{5}$, J. Esper ${ }^{6}$, C. Huntingford7 , G. Helle ${ }^{8}$, K. Treydte $^{1}$, N. E. \\ Zimmermann1, G. H. Schleser8,9, A. Ahlström ${ }^{10,11}$, P. Ciais ${ }^{4}$, P. Friedlingstein ${ }^{12}$, S. Levis ${ }^{13}$, M. Lomas $^{14}$, S. \\ Sitch $^{12}$, N. Viovy ${ }^{4}$, L. Andreu-Hayles ${ }^{15}$, Z. Bednarz ${ }^{16}$, F. Berninger ${ }^{17}$, T. Boettger ${ }^{18}$, C. M. D'Alessandro ${ }^{19}$, V. \\ Daux $^{4}$, M. Filot 20 , M. Grabner ${ }^{21}$, E. Gutierrez ${ }^{22}$, M. Haupt ${ }^{18}$, E. Hilasvuori23, H. Jungner ${ }^{17}$, M. Kalela-Brundin ${ }^{24}$, \\ M. Krapiec 25 , M. Leuenberger 2,20 , N. J. Loader ${ }^{26}$, H. Marah27, V. Masson-Delmotte ${ }^{4}$, A. Pazdur ${ }^{28}$, S. \\ Pawelczyk ${ }^{28}$, M. Pierre4 ${ }^{4}$ O. Planells ${ }^{22}$, R. Pukiene ${ }^{29}$, C. E. Reynolds-Henne ${ }^{5}$, K. T. Rinne ${ }^{5}$ A. Saracino ${ }^{30}$, E. \\ Sonninen ${ }^{17}$, M. Stievenard ${ }^{4}$, V. R. Switsur ${ }^{31+}$, M. Szczepanek28, E. Szychowska-Krapiec ${ }^{25}$, L. Todaro ${ }^{19}$, J. S. \\ Waterhouse ${ }^{31}$, and $M$. Weig| ${ }^{32}$ (Author affiliations at the end of the paper.)
}

The Earth's carbon and hydrologic cycles are intimately coupled by gas exchange through plant stomata ${ }^{1-3}$. However, uncertainties in the magnitude ${ }^{4-6}$ and consequences ${ }^{7,8}$ of the physiological responses 9,10 of plants to elevated $\mathrm{CO}_{2}$ in natural environments hinders modelling of terrestrial water cycling and carbon storage ${ }^{11}$. Here we use annually resolved long-term $\delta^{13} \mathrm{C}$ tree-ring measurements across a European forest network to reconstruct the physiologically driven response of intercelIular $\mathrm{CO}_{2}\left(C_{i}\right)$ caused by atmospheric $\mathrm{CO}_{2}\left(C_{a}\right)$ trends. When removing meteorological signals from the $\delta^{13} \mathrm{C}$ measurements, we find that trees across Europe regulated gas exchange so that for one ppmv atmospheric $\mathrm{CO}_{2}$ increase, $\mathrm{C}_{\mathrm{i}}$ increased by $\sim 0.76$ ppmv, most consistent with moderate control towards a constant $C_{i} / C_{\mathrm{a}}$ ratio. This response corresponds to twentiethcentury intrinsic water-use efficiency (iWUE) increases of $14 \pm 10$ and $22 \pm 6 \%$ at broadleaf and coniferous sites, respectively. An ensemble of process-based global vegetation models shows similar $\mathrm{CO}_{2}$ effects on iWUE trends. Yet, when operating these models with climate drivers reintroduced, despite decreased stomatal opening, 5\% increases in European forest transpiration are calculated over the twentieth century. This counterintuitive result arises from lengthened growing seasons, enhanced evaporative demand in a warming climate, and increased leaf area, which together oppose effects of $\mathrm{CO}_{2}$-induced stomatal closure. Our study questions changes to the hydrological cycle, such as reductions in transpiration and air humidity, hypothesized to result from plant responses to anthropogenic emissions.

Annually, $\sim 40,000 \mathrm{~km}^{3}$ or $\sim 60 \%$ of the total evapotranspiration over land enters the atmosphere via transpiration ${ }^{2,12}$. Most of this is from plants with the $\mathrm{C} 3$ carbon assimilation pathway, including economically important crops (for example, wheat and rice) and broadleaf and coniferous trees, totalling $\sim 95 \%$ of the living terrestrial plant biomass ${ }^{13}$. Laboratory and free-air $\mathrm{CO}_{2}$ enrichment (FACE) experiments $s^{3,9,10}$ indicate that increasing atmospheric $\mathrm{CO}_{2}$ concentrations affect $\mathrm{C} 3$ stomatal conductance and photosynthesis. Modelling assessments incorporating knowledge of these physiological mechanisms suggest substantial impacts on the
Earth's coupled climate-hydrologic-carbon systems. Besides impacts on future carbon sinks ${ }^{14}$, possible climatic consequences from physiological responses to increased $\mathrm{CO}_{2}$ concentrations include changes in transpiration that may well affect regional hydroclimate and flood risks ${ }^{3,15,16}$.

The IPCC Fifth Assessment Report emphasizes the high uncertainties still surrounding plant physiological responses to increasing $\mathrm{CO}_{2}$ concentrations ${ }^{11}$. For example, a recent analysis of eddy-covariance time series $^{6}$ inferred that northern boreal and temperate forests regulate stomatal conductance to maintain constant intercellular $\mathrm{CO}_{2}$ concentrations, $C_{\mathrm{i}}$. Maintaining a constant $C_{\mathrm{i}}$ in the past one to two decades implies a very strong physiological response, contradicting earlier observational and experimental data used to optimize parameterizations of the land components of climate models ${ }^{17}$. To reduce such uncertainty, we take advantage of additional measurements that have not traditionally been used to verify terrestrial ecosystem model functioning, namely tree-ring carbon isotope data.

The diffusion of $\mathrm{CO}_{2}$ through stomata from the external leaf boundary layer to the leaf-internal photosynthesis sites, as well as the enzymatic reactions during carboxylation, causes discrimination of ${ }^{13} \mathrm{C}$ in $\mathrm{CO}_{2}$ (ref. 18). Knowledge of these fractionation processes allows $C_{\mathrm{i}}$ to be reconstructed from the stable carbon isotope measurements $\left(\delta^{13} \mathrm{C}\right)$ on alpha-cellulose extracted from trees' annual growth rings ${ }^{4,19}$. In particular, for C3 plants, $C_{\mathrm{i}}$ can be reconstructed from ice-core and instrumental measurements of $\mathrm{CO}_{2}$ concentration $\left(C_{\mathrm{a}}\right)$ and its atmospheric $\delta^{13} \mathrm{C}$ signature, and from the well-established values of isotope discrimination constants from carboxylation and diffusion of $\mathrm{CO}_{2}$ through leaves (Methods). Yet, this crucial information held in tree-ring measurements has been underused in testing dynamic global vegetation models (DGVMs), despite providing key information on stomatal functioning. Furthermore, knowledge of $C_{\mathrm{i}}$ and the well-established $C_{\mathrm{a}}$ time series quantifies intrinsic water-use efficiency from the diffusion equation $\left[\mathrm{iWUE}=A / g=\left(C_{\mathrm{a}}-C_{\mathrm{i}}\right) / 1.6\right]$, linking leaf-level $\mathrm{CO}_{2}$ assimilation rate $(A)$ to stomatal conductance $(g)$, for the known $C_{\mathrm{a}}-C_{\mathrm{i}}$ difference. Although actual water consumption also varies 


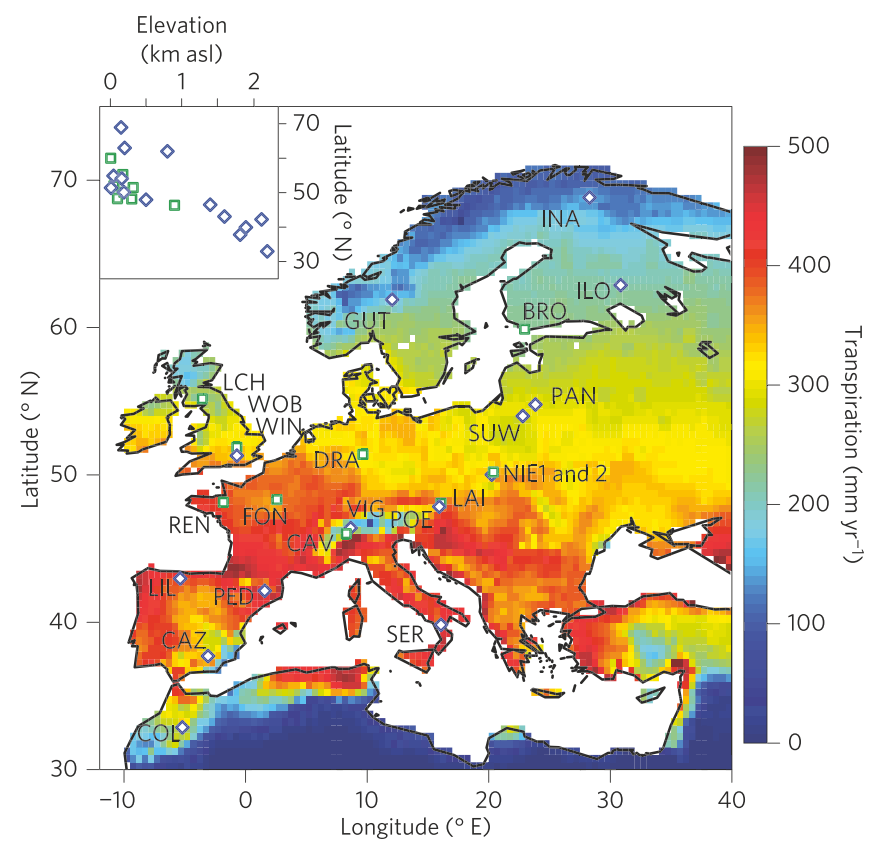

Figure 1 | European forest study sites. Locations of the 9 broadleaf (green squares) and 14 coniferous (blue diamonds) ISONET sites (labels are site abbreviations; see Supplementary Table 1). Conifer sites are distributed from northern Fennoscandia to the Mediterranean regions, with broadleaf species concentrated in central Europe. The negative correlation between site elevation and latitude (inset) reflects the elevational decrease in treeline as well as ecological and anthropogenic effects dictating long-lived tree locations. Coloured background shows modelled annual transpiration over the past decade. asl, above sea level.

with environmental conditions and plant biomass, the iWUE is a key measure of potential water costs to maintain a given rate of carbon assimilation per unit leaf area. Attributing the $\mathrm{CO}_{2}$ influence on iWUE also should account for impacts of climate variability on isotope discrimination owing to both the lower $C_{\mathrm{i}}$ at more temperate sites $^{4}$ (Supplementary Figs 1 and 2) and the strong inter-annual to long-term climate-driven variability evident in tree-ring $\delta^{13} \mathrm{C}$ time series ${ }^{20}$ (Supplementary Fig. 3).

Our tree-ring data set comprises two of the most important genera (Quercus and Pinus) from the broadleaf (9 stands) and coniferous (14 stands) tree types in Europe. Geographically, data span from northern Scandinavia to Morocco and the United Kingdom to Poland (Fig. 1 and Supplementary Table 1). Annual resolution for all sites throughout the twentieth century permits assessment of inter-annual to long-term climatic impacts, enabling identification of intercellular $\mathrm{CO}_{2}$ trends driven directly by rising atmospheric $\mathrm{CO}_{2}$ concentrations (Methods).

Our long-term tree-ring measurements show that simultaneous to the $\sim 70$ ppmv twentieth century increase ${ }^{11}$ in $C_{\mathrm{a}}$, the annually resolved tree-ring network yields a $44 \pm 10$ ppmv $C_{\mathrm{i}}$ increase (Fig. 2). These trends are consistent with conclusions drawn from metaanalyses of iWUE responses from independent tree-ring data sets ${ }^{21}$, yet incompatible with a recent investigation ${ }^{6}$ of ecosystem-level water-use efficiency concluding $C_{\mathrm{i}}$ remained constant over the most recent decades. Despite discrepancies previously identified between empirical and model evidence ${ }^{6}$, both the absolute $C_{\mathrm{i}}$ values and their twentieth century changes are well captured by DGVM ensemble results (Fig. 2a inset). Furthermore, we find that $C_{\mathrm{i}}$ depends strongly on climate variability, as evidenced by significant $(p<0.01)$ correlations with temperature and precipitation fluctuations $(R=-0.55$ and 0.57 , respectively, after detrending data with a spline). Correlation might not reflect causality, but our statistical

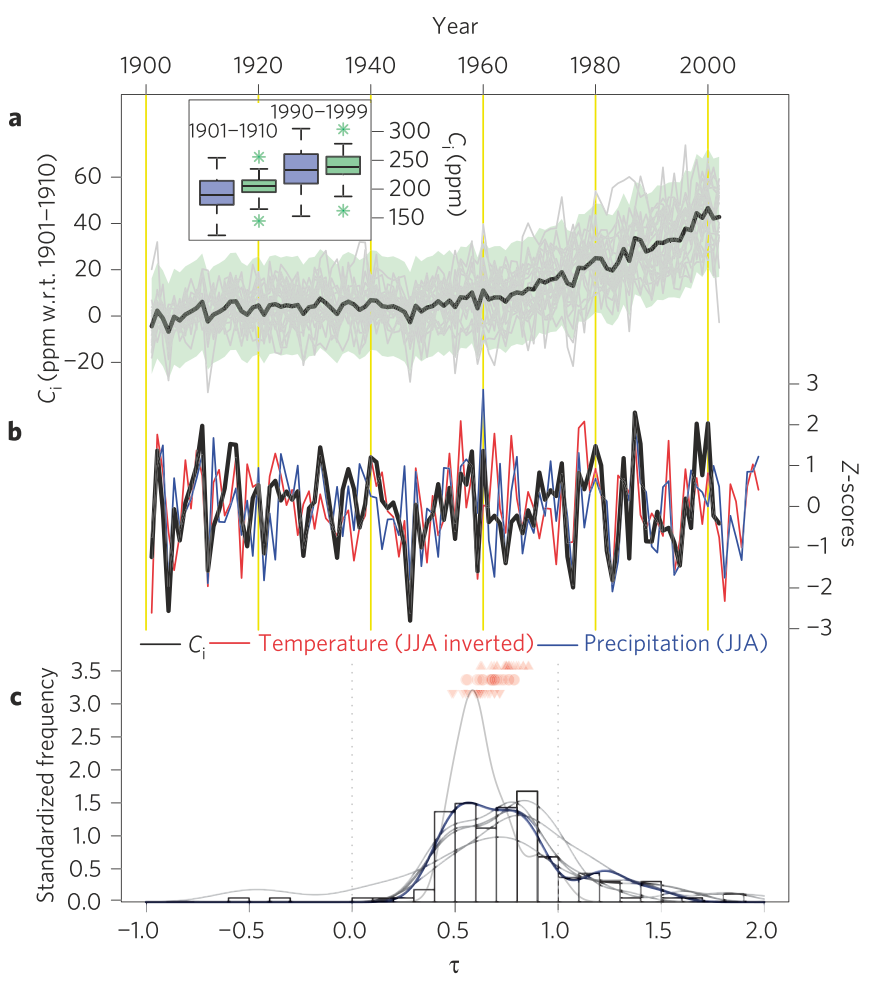

Figure 2 | Changes in intercellular $\mathrm{CO}_{2}$ concentrations. a, Reconstructed relative to 1901-1910 levels from isotope measurements from all 23 sites in Europe (grey), their mean (black), and uncertainties (light green). The inset shows DGVM simulated (blue) and tree-ring reconstructed (green) $C_{i}$. Asterisks denote uncertainties. b, High-pass-filtered mean from a (black) together with summer temperature and precipitation averaged from the instrumental gridpoints nearest to the sites. $\mathbf{c}$, Increase in intercellular $\mathrm{CO}_{2}$

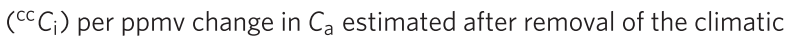
component from individual sites (see Methods). Smoothed curves in c are density estimates considering the climatic influence for five instrumental parameters (grey) and their first principal component at each site (blue). Values of $\tau$ less than 1 indicate increases in ${ }^{c c}$ iWUE. $\tau$ values in the $0.5-0.7$ range (red circles) and their upper and lower confidence limits (red triangles) would be required to maintain a constant ${ }^{c c} C_{\mathrm{i}} / C_{\mathrm{a}}$ ratio. JJA stands for June, July and August.

tests (Methods) suggest stronger control of $C_{\mathrm{i}}$ variability from precipitation fluctuations towards the Mediterranean regions (probably from rainfall controls on stomatal opening via soil moisture). In contrast, maximum temperature variability was more strongly correlated with $C_{\mathrm{i}}$ fluctuations towards Scandinavia, possibly due to associations with increased radiation/photosynthesis and enhanced vapour pressure deficit (Supplementary Fig. 3).

We thus estimate changes in $C_{\mathrm{i}}$ driven purely by $C_{\mathrm{a}}$ (ppmv per ppmv)-this physiological response to $\mathrm{CO}_{2}$, defined as $\tau-$ by accounting for the influence of climate variation on tree-ring $\delta^{13} \mathrm{C}$. These 'climate-corrected' estimates-that is, climate signal removed - are denoted by the superscript ${ }^{\text {(cc) }}$ prefix; see methods and Supplementary Figs 5-7. We find that for every ppmv increase in $C_{\mathrm{a}}$ over the twentieth century, the ${ }^{c c} C_{\mathrm{i}}$, increased by $0.76 \pm 0.28 \mathrm{ppmv}$ (median \pm s.d.; Fig. 2c). Broadleaves have higher $\tau$ values than conifers (median 0.81 and 0.65 , respectively) over the twentieth century. Relative to three leaf-level gas-exchange set-points debated in the literature, namely: plant maintenance of a constant $C_{\mathrm{i}}$ (ref. 6), constant $C_{\mathrm{i}} / C_{\mathrm{a}}$ ratio $^{22}$, or constant difference ${ }^{5}$ between $C_{\mathrm{a}}$ and $C_{\mathrm{i}}$, we find greatest consistency with the constant $C_{\mathrm{i}} / C_{\mathrm{a}}$ ratio hypothesis. In detail, we cannot statistically distinguish $(p=0.98)$ the conifer responses from the null hypothesis of a constant $C_{\mathrm{i}} / C_{\mathrm{a}}$ ratio (that 


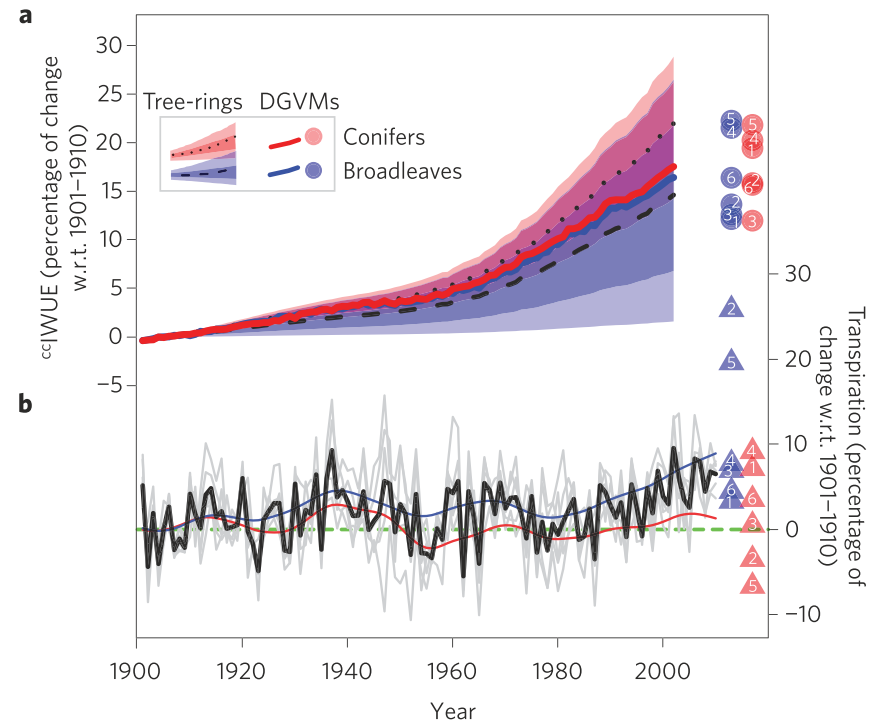

Figure 3 | Water-use efficiency and transpiration variability relative to 1901-1910. Temporal changes in the twentieth century European water balance. $\mathbf{a},{ }^{c c}$ iWUE upper and lower deciles (light shaded), the 22nd and 78th percentiles (dark shaded), and median estimates (dashed) for the broadleaf and conifer sites until 2002. Ensemble means for the DGVM modelled iWUE changes for PFTs (solid lines) together with decadal mean values around 2002 (circles: $1=\mathrm{CLM} 4 \mathrm{CN} ; 2=\mathrm{LPJ} ; 3=$ LPJ-GUESS; $4=$ SDGVM; $5=$ TRIFFID; $6=$ ORCHIDEE. b, Changes in transpiration for the European tree PFTs for the six ensemble members (grey), their mean (black), and for the smoothed broadleaf (blue) and coniferous evergreen (red) ensemble means. Coloured triangles as in a for 2001-2010.

would be associated with $\tau$ values between 0.55 and 0.79 ). The empirical response at the broadleaf sites (median $\tau=0.81$ ) is intermediate to hypothesis for a constant $C_{\mathrm{i}} / C_{\mathrm{a}}$ ratio $(\tau$ between $0.68-0.79)$ and $C_{\mathrm{a}}-C_{\mathrm{i}}$ set-points $(\tau=1)$. This finding importantly allows us to benchmark the plant responses to $\mathrm{CO}_{2}$ while mitigating the confounding climatic variation.

When our climate-corrected estimates of $C_{\mathrm{i}}$ are used to derive ${ }^{c c}$ iWUE, we find that $\sim 66 \%$ of the European broadleaf and $\sim 93 \%$ of the conifer sites show an increase in "ciWUE. Relative to the 1901-1910 reference period, the average increase in "ciWUE was $14 \pm 10 \%$ at the broadleaf sites and $22 \pm 6 \%$ at the conifer sites during the twentieth century (Fig. 3). These results are consistent with ecophysiological literature that evergreen plants (and particularly sclerophylls) may show greater increases in WUE metrics (for example, based on transpiration or alternatively stomatal conductance) due to rigid leaf architecture ${ }^{23}$ and a greater coupling with atmospheric boundary layer processes ${ }^{24}$ and associated feedbacks from changes in surface humidity. Without exclusion of climate effects we obtain larger iWUE trends of approximately $30 \%$ for the same period (Supplementary Fig. 4). This empirical evidence supports previous ${ }^{4}$ and new (see below) model results suggesting contributions to iWUE due to warming/drying over Europe in addition to the physiological responses to elevated $\mathrm{CO}_{2}$. This affects particularly strongly broadleaf sites in central Europe, where warming is greatest. Warming/drying trends $s^{6,19,22}$ tend to lower the $C_{\mathrm{i}}$ rate of increase, resulting in a larger $C_{\mathrm{a}}-C_{\mathrm{i}}$ difference, a higher iWUE, and estimates closer to a constant $C_{\mathrm{i}}$ (Supplementary Fig. 8).

Our long-term estimates of climate-corrected $C_{\mathrm{i}}$ and ${ }^{\mathrm{cc}} \mathrm{iWUE}$ provide a unique test on the ability of DGVM to reproduce (or not) physiological responses to higher ambient $\mathrm{CO}_{2}$. We accordingly perform factorial experiments with an ensemble of DGVMs that isolate modelled plant responses to contemporary
$\mathrm{CO}_{2}$ trends only. Simulated iWUE responses fall between the $\delta^{13} \mathrm{C}$-derived observations for the broadleaf and conifers (Fig. 3a), but the DGVM results are not statistically different between the broadleaf and conifer plant functional types (PFTs), with individual ensemble members showing between a 12 and $22 \%$ increase in European ${ }^{c c}$ iWUE. Hence, from our values above, results indicate consistency between the modelled and empirical ${ }^{c c}$ iWUE response. Although previous investigations ${ }^{25}$ show coherence between tree-ring and leaf measurements for $C_{\mathrm{i}}$, the extent to which both tree rings and models integrate canopy and other physiological processes requires investigation. This includes post-photosynthetic discrimination, storage and remobilization of carbohydrates, and how model predictions are influenced by simplified representations of canopy processes and vegetation dynamics. Various WUE metrics (Supplementary Figs 8-11), model configuration and structural differences in formulation ${ }^{24}$ of, for example, photosynthesis, stomatal conductance, transpiration demand or the non-water stressed $C_{\mathrm{i}} / C_{\mathrm{a}}$ ratio (Supplementary Table 3) furthermore contribute to some ensemble spread. With climate factors reintroduced to the simulations, we observe additional enhancement of iWUE. Furthermore, in line with the findings of ref. 6 based on ecosystem-level measurements of productivity and water loss, strongest increases were found when using their definition of WUE, with multiplication by vapour pressure deficit (VPD; Supplementary Figs 9-11).

Land-surface models solve equations for $C_{i}$, photosynthesis $(A)$ and stomatal conductance $(g)$, to predict the exchange of water between the land and atmosphere. However, plant responses, including stomatal conductance, to changing $\mathrm{CO}_{2}$ remain particularly uncertain for long timescales ${ }^{11}$. Prescription of $C_{\mathrm{i}} / C_{\mathrm{a}}$ in models closes the equations, and $g$ thus becomes a diagnostic. Our analysis of $C_{\mathrm{i}} / C_{\mathrm{a}}$, using $C_{\mathrm{i}}$ derived from tree-ring measurements, provides strong evidence for the numerical value that this ratio should take, and therefore contributes a much needed constraint on projections by land-surface models. The general agreement between $\delta^{13} \mathrm{C}$-derived and process-modelled $C_{\mathrm{i}}$ estimates suggests accurately modelled stomatal control, a major determinant in trends of land evapotranspiration.

Model simulations incorporating both $\mathrm{CO}_{2}$ and climatic drivers tend to show increased twentieth century transpiration across the European continent (Fig. 3b). Inter-annual transpiration variability over Europe of all PFTs-hence including non-trees-is of the order of a few per cent. However, five of the six ensemble members show $\sim 5 \%$ increased $\left(+56 \mathrm{~km}^{3} \mathrm{yr}^{-1}\right.$ on average) transpiration in the most recent (2001-2010) decade relative to the beginning of the simulations (1901-1910). When considering just trees, these century-timescale changes fall in a range of $4-9 \%$, with the evergreen conifer and deciduous broadleaf PFTs showing on average $2 \%$ (range -7 to $9 \%$ ) and $11 \%$ (3 to $26 \%$ ) increases, respectively (see also Supplementary Figs 15 and 16).

Assessed globally, despite indications that recent drought stress has perhaps dampened overall productivity ${ }^{26}$ and possibly total transpiration ${ }^{12}$, we find tendencies for stable or increasing transpiration from tree PFTs for $66 \%$ of ensemble members (Supplementary Fig. 16). Hence, model results suggest that any $\mathrm{CO}_{2}$-driven (and for some regions, drought-induced) reductions in stomatal conductance simulated for most models and PFTs (Supplementary Figs 12-14) are insufficient to outweigh other factors which both models and observations suggest can increase tree transpiration, such as enhanced leaf-area index ${ }^{27}$, lengthened growing season, and increased evaporative demand ${ }^{11}$.

Interactions among various climatic and physiological responses to $\mathrm{CO}_{2}$ such as leaf-area increase have been investigated in individual modelling studies ${ }^{1,16,27}$, yet a comprehensive meta-analysis ${ }^{28}$ regarding anthropogenic impacts on the terrestrial water cycle recently noted "...there is disagreement even at the level of the 
sign of net change to runoff from twentieth century evolutions of meteorological forcing, induced primarily by human activity, and from combined plant physiological responses to rising $\mathrm{CO}_{2} \ldots$.. Furthermore, global-scale assessments may miss important regional variation and processes. Our ensemble of vegetation models contributes to both accurately characterizing and reducing this uncertainty. First, we find a broad consensus in the model responses regarding transpiration trends in Europe (Fig. 3) and globally (Supplementary Fig. 16). This is relevant, given the possible uncertainties represented by the various formulations and parameterizations underlying individual vegetation models (Supplementary Table 3; ref. 24). Furthermore, we note the differences in modelled responses between the broadleaf and coniferous plant functional types (Fig. 3b and Supplementary Figs 9, 14-16). Such plant functional type or even species-specific ${ }^{3,29}$ responses have not received attention in previous large-scale DGVM studies ${ }^{1,15,27}$ of plant responses to $\mathrm{CO}_{2}$, and we hypothesize will have biome-specific consequences on the land-atmosphere water fluxes.

Evidence supporting our conclusions with plausible and observed mechanisms counteracting $\mathrm{CO}_{2}$-induced reductions in the land-atmosphere water vapour flux already exists. For example, in a changing climate, emergent canopy and ecosystem processes including atmospheric feedbacks may alter transpiration; various $\mathrm{CO}_{2}$-enrichment experiments have already found smaller than expected reductions in ecosystem transpiration, particularly for coniferous trees ${ }^{9}$. Furthermore, the increased seasonally averaged LAI in our simulations (Supplementary Figs 12 and 14) is backed by observed growing season trends ${ }^{11}$ and $\mathrm{CO}_{2}$-driven increases in leaf area in natural environments ${ }^{30}$. Although our data from the past century strengthen the credibility of DGVMs, other sources of uncertainty remain for forward projections. Over longer periods, trends in stomatal conductance, WUE and LAI may be confounded by major changes in nutrients and pollutants $\mathrm{s}^{31,32}$, persistent adjustment to water availability ${ }^{12}$, cavitation, and plant responses to $\mathrm{CO}_{2}$ concentrations last experienced on geologic timescales ${ }^{33}$. Some of these factors are only now being implemented in DGVMs, for which knowledge of $C_{\mathrm{i}}$ will also aid further model testing.

Detailed analyses of tree-ring-based measurements provide an accurate determination of how both climate and atmospheric $\mathrm{CO}_{2}$ concentrations, $C_{\mathrm{a}}$, have influenced intercellular $\mathrm{CO}_{2}$ concentration, $C_{i}$, during the past century. On average we find that increases in $C_{\mathrm{i}}$ are $76 \%$ the size of increases in $C_{\mathrm{a}}$. For conifers, in particular, the temporal evolution of $C_{\mathrm{i}}$ is such that $C_{\mathrm{i}} / C_{\mathrm{a}}$ is nearly constant. This independent knowledge of $C_{\mathrm{i}}$ allows a particularly strong test to be made of DGVMs, and especially as this quantity is usually only calculated implicitly in such models, being dependent on model formulations of both assimilation and stomatal opening. We are encouraged to find that DGVMs perform well for this parameter, and this gives confidence in their projection of transpiration, a flux that is important for future land-surface climate impacts. In fact, our results show that anthropogenic $\mathrm{CO}_{2}$ emissions have already caused large-scale $\mathrm{CO}_{2}$-driven physiologically induced changes and that, despite associated stomatal closure (which, occurring in isolation, might be expected to reduce transpiration), this water-vapour flux has generally increased over Europe. These processes are expected to lead to two counteracting effects on climate: on one hand, enhanced evapotranspiration is expected to reduce surface temperature due to increased latent heat loss; on the other hand, greater transpiration could enhance warming due to water vapour and soil hydrology feedbacks, as already evidenced during recent heat waves ${ }^{34}$, but for which a large dispersion has been reported amongst climate change projections $s^{35}$. Future generations of fully coupled climate models will better predict this balance, but can accurately do so only with robust land-surface descriptions. Our use of novel data to constrain an ensemble of terrestrial ecosystem models helps significantly towards achieving this goal.

\section{Methods}

Methods and any associated references are available in the online version of the paper.

Received 14 August 2014; accepted 10 March 2015;

published online 11 May 2015

\section{References}

1. Cao, L., Bala, G., Caldeira, K., Nemani, R. \& Ban-Weiss, G. Importance of carbon dioxide physiological forcing to future climate change. Proc. Natl Acad. Sci. USA 107, 9513-9518 (2010).

2. Schlesinger, W. H. \& Jasechko, S. Transpiration in the global water cycle. Agric. Forest Meteorol. 189-190, 115-117 (2014).

3. Leuzinger, S. \& Körner, C. Water savings in mature deciduous forest trees under elevated $\mathrm{CO}_{2}$. Glob. Change Biol. 13, 2498-2508 (2007).

4. Saurer, M. et al. Spatial variability and temporal trends in water-use efficiency of European forests. Glob. Change Biol. 20, 3700-3712 (2014).

5. Marshall, J. D. \& Monserud, R. A. Homeostatic gas-exchange parameters inferred from ${ }^{13} \mathrm{C} /{ }^{12} \mathrm{C}$ in tree rings of conifers. Oecologia 105, 13-21 (1996).

6. Keenan, T. F. et al. Increase in forest water-use efficiency as atmospheric carbon dioxide concentrations rise. Nature 499, 324-327 (2013).

7. Koutavas, A. $\mathrm{CO}_{2}$ fertilization and enhanced drought resistance in Greek firs from Cephalonia Island, Greece. Glob. Change Biol. 19, 529-539 (2013).

8. van der Sleen, P. et al. No growth stimulation of tropical trees by 150 years of $\mathrm{CO}_{2}$ fertilization but water-use efficiency increased. Nature Geosci. 8, 24-28 (2015)

9. Ainsworth, E. A. \& Rogers, A. The response of photosynthesis and stomatal conductance to rising $\left[\mathrm{CO}_{2}\right]$ : Mechanisms and environmental interactions. Plant Cell Environ. 30, 258-270 (2007).

10. Drake, B. G., Gonzàlez-Meler, M. A. \& Long, S. P. More efficient plants: A consequence of rising atmospheric $\mathrm{CO}_{2}$ ? Annu. Rev. Plant Biol. 48, 609-639 (1997)

11. IPCC Climate Change 2013: The Physical Science Basis (eds Stocker, T. F. et al.) (Cambridge Univ. Press, 2013)

12. Jung, M. et al. Recent decline in the global land evapotranspiration trend due to limited moisture supply. Nature 467, 951-954 (2010).

13. Still, C. J., Berry, J. A., Collatz, G. J. \& DeFries, R. S. Global distribution of C-3 and C-4 vegetation: Carbon cycle implications. Glob. Biogeochem. Cycle 17, 14 (2003).

14. Shevliakova, E. et al. Historical warming reduced due to enhanced land carbon uptake. Proc. Natl Acad. Sci. USA 110, 16730-16735 (2013).

15. Gedney, N. et al. Detection of a direct carbon dioxide effect in continental river runoff records. Nature 439, 835-838 (2006).

16. Betts, R. A. et al. Projected increase in continental runoff due to plant responses to increasing carbon dioxide. Nature 448, 1037-1041 (2007).

17. Medlyn, B. E. et al. Reconciling the optimal and empirical approaches to modelling stomatal conductance. Glob. Change Biol. 17, 2134-2144 (2011).

18. Farquhar, G. D., Ehleringer, J. R. \& Hubick, K. T. Carbon isotope discrimination and photosynthesis. Annu. Rev. Plant Physiol. Plant Mol. Biol. 40, 503-537 (1989).

19. Feng, X. H. Trends in intrinsic water-use efficiency of natural trees for the past 100-200 years: A response to atmospheric $\mathrm{CO}_{2}$ concentration. Geochim. Cosmochim. Acta 63, 1891-1903 (1999).

20. Treydte, K. et al. Signal strength and climate calibration of a European tree-ring isotope network. Geophys. Res. Lett. 34, L24302 (2007).

21. Peñuelas, J., Canadell, J. G. \& Ogaya, R. Increased water-use efficiency during the 20th century did not translate into enhanced tree growth. Global Ecology Biogeography 20, 597-608 (2011).

22. Saurer, M., Siegwolf, R. T. W. \& Schweingruber, F. H. Carbon isotope discrimination indicates improving water-use efficiency of trees in northern Eurasia over the last 100 years. Glob. Change Biol. 10, 2109-2120 (2004).

23. Niinemets, U., Flexas, J. \& Penuelas, J. Evergreens favored by higher responsiveness to increased $\mathrm{CO}_{2}$. Trends Ecol. Evol. 26, 136-142 (2011).

24. De Kauwe, M. G. et al. Forest water use and water use efficiency at elevated $\mathrm{CO}_{2}$ : A model-data intercomparison at two contrasting temperate forest FACE sites. Glob. Change Biol. 19, 1759-1779 (2013).

25. Klein, T. et al. Association between tree-ring and needle $\delta^{13} \mathrm{C}$ and leaf gas exchange in Pinus halepensis under semi-arid conditions. Oecologia 144, 45-54 (2005).

26. Zhao, M. S. \& Running, S. W. Drought-induced reduction in global terrestrial net primary production from 2000 through 2009. Science 329, 940-943 (2010).

27. Piao, S. L. et al. Changes in climate and land use have a larger direct impact than rising $\mathrm{CO}_{2}$ on global river runoff trends. Proc. Natl Acad. Sci. USA 104, 15242-15247 (2007) 
28. Sterling, S. M., Ducharne, A. \& Polcher, J. The impact of global land-cover change on the terrestrial water cycle. Nature Clim. Change 3, 385-390 (2013).

29. Babst, F. et al. Site- and species-specific responses of forest growth to climate across the European continent. Glob. Ecol. Biogeogr. 22, 706-717 (2013).

30. Donohue, R. J., Roderick, M. L., McVicar, T. R. \& Farquhar, G. D. Impact of $\mathrm{CO}_{2}$ fertilization on maximum foliage cover across the globe's warm, arid environments. Geophys. Res. Lett. 40, 3031-3035 (2013).

31. Boettger, T., Haupt, M., Friedrich, M. \& Waterhouse, J. S. Reduced climate sensitivity of carbon, oxygen and hydrogen stable isotope ratios in tree-ring cellulose of silver fir (Abies alba Mill.) influenced by background $\mathrm{SO} 2$ in Franconia (Germany, Central Europe). Environ. Pollut. 185, 281-294 (2014).

32. Holmes, C. D. Air pollution and forest water use. Nature 507, E1-E2 (2014).

33. Cowling, S. A. \& Field, C. B. Environmental control of leaf area production: Implications for vegetation and land-surface modeling. Glob. Biogeochem. Cycle 17, 1007 (2003).

34. Shongwe, M. E., Graversen, R. G., van Oldenborgh, G. J., van den Hurk, B. \& Doblas-Reyes, F. J. Energy budget of the extreme Autumn 2006 in Europe. Clim. Dynam. 36, 1055-1066 (2011).

35. Cattiaux, J., Douville, H. \& Peings, Y. European temperatures in CMIP5: Origins of present-day biases and future uncertainties. Clim. Dynam. 41, 2889-2907 (2013).

\section{Acknowledgements}

We thank C. Körner, S. Seneviratne, and A. Gessler for comments, the European Union projects ISONET (EVK2-2001-00237), Carbo-Extreme (226701) and Millennium (017008), the Swiss National Science Foundation (iTREE CRSII3_136295), and N.J.L. the UK NERC (NE/B501504) and C3W for funding.

\section{Author contributions}

D.C.F., B.P., M. Saurer, J.E. and G.H.S. designed the study, with input from C.H., G.H. and N.E.Z. D.C.F., B.P. and M. Saurer performed the analyses with input from J.E., C.H. and G.H.S. All authors contributed to discussion, interpretation, and the development of the data set and ISONET program (devised by G.H.S., G.H. and N.J.L.) or the TRENDY model intercomparison project (coordinated by S.S. and P.F.). D.C.F., B.P. and C.H. led the writing of this paper.

\section{Additional information}

Supplementary information is available in the online version of the paper. Reprints and permissions information is available online at www.nature.com/reprints.

Correspondence and requests for materials should be addressed to D.C.F. or B.P.

\section{Competing financial interests}

The authors declare no competing financial interests.

\footnotetext{
${ }^{1}$ Swiss Federal Research Institute WSL, 8903 Birmensdorf, Switzerland. ${ }^{2}$ Oeschger Centre for Climate Change Research, University of Bern, 3012 Bern, Switzerland. ${ }^{3}$ Institute on Ecosystems and Department of Ecology, Montana State University, Bozeman, Montana 59717, USA. ${ }^{4}$ Laboratoire des Sciences du Climat et de l'Environnement (CEA-CNRS-UVSQ, UMR8212), Institut Pierre Simon Laplace, 91191 Gif-sur-Yvette, France. ${ }^{5}$ Paul Scherrer Institute, 5232 Villigen, Switzerland. ${ }^{6}$ Department of Geography, Johannes Gutenberg University, 55099 Mainz, Germany. ${ }^{7}$ Centre for Ecology and Hydrology, Wallingford, Oxfordshire OX10 8BB, UK. ${ }^{8}$ Helmholtz-Centre Potsdam. German Centre for Geosciences-GFZ, 14473 Potsdam, Germany.

${ }^{9}$ Forschungszentrum Jülich GmbH, 52428 Jülich, Germany. ${ }^{10}$ Department of Physical Geography and Ecosystem Science, Lund University, Lund SE-223 62, Sweden. ${ }^{11}$ Department of Earth System Science, School of Earth, Energy and Environmental Sciences, Stanford University, Stanford, California 94305, USA. ${ }^{12}$ University of Exeter, Exeter EX4 4QF, UK. ${ }^{13}$ National Center for Atmospheric Research, Boulder, Colorado 80301, USA. ${ }^{14}$ University of Sheffield, Sheffield S10 2TN, UK. ${ }^{15}$ Lamont-Doherty Earth Observatory, Palisades, New York 10964, USA. ${ }^{16}$ Agricultural University, 31-120 Krakow, Poland. ${ }^{17}$ University of Helsinki, 00014 Helsinki, Finland. ${ }^{18}$ Department of Catchment Hydrology, UFZ-Helmholtz Centre for Environmental Research, 06120 Halle, Germany. ${ }^{19}$ University of Basilicata, 85100 Potenza, Italy. ${ }^{20}$ University of Bern, 3012 Bern, Switzerland. ${ }^{21}$ University of Natural Resources and Life Science (BOKU), 1180 Vienna, Austria. ${ }^{22}$ Department of Ecology, Universitat Barcelona, 08028 Barcelona, Spain. ${ }^{23}$ Finnish Environment Institute, 00251 Helsinki, Finland. ${ }^{24}$ Forestry Museum, 92123 Lycksele, Sweden. ${ }^{25} \mathrm{AGH}$-University of Science and Technology, 30-059 Krakow, Poland. ${ }^{26}$ Department of Geography, Swansea University, Swansea SA2 8PP, UK. ${ }^{27}$ CNESTEN, 10001 Rabat, Morocco. ${ }^{28}$ Silesian University of Technology, 44-100 Gliwice, Poland. ${ }^{29}$ Vytautas Magnus University, 44248 Kaunas, Lithuania. ${ }^{30}$ University of Naples "Federico II", 80055 Portici, Italy. ${ }^{31}$ Anglia Ruskin University, Cambridge CB1 1PT, UK.

${ }^{32}$ Holzforschung Austria, 1030 Vienna, Austria. †Deceased. *e-mail: david.frank@wsl.ch; benjamin.poulter@montana.edu
} 


\section{Methods}

Tree-ring network and measurements. Annually resolved tree-ring stable carbon isotope $\left(\delta^{13} \mathrm{C}\right)$ measurements (1901-2002) were performed for 23 sites (14 conifer and 9 broadleaf) around the European continent. Increment cores were collected from numerous trees at each site, and the annual radial increments were cross-dated and measured following standard dendrochronological procedures. At least two cores from four or more dominant trees per site were selected for subsequent isotope analyses. Sample preparation and measurement involved carefully segmenting the cores along annual ring boundaries, and for the majority of sites all rings of a given year were pooled together. Homogenization (milling) and alpha-cellulose preparation followed consistent and standard protocols, with $\delta^{13} \mathrm{C}$ analysed by mass spectrometry on $\mathrm{CO}_{2}$ obtained from combustion of the alpha-cellulose. Changes in intercellular $\mathrm{CO}_{2}$ concentrations $\left(C_{\mathrm{i}}\right)$ and the intrinsic water-use efficiency (iWUE) were reconstructed by employing known relationships among plant-gas exchange, potential water loss, and related isotopic discrimination ${ }^{18}$, modified to account for post-photosynthetic discrimination in plant tissues. See Supplementary Methods for a more detailed description of the study sites, measurement procedures, formulae used to compute $C_{\mathrm{i}}$ and iWUE, and associated uncertainties.

Climatic and $\mathrm{CO}_{2}$ controls on water-use efficiency. To isolate the impacts of changes in atmospheric $\mathrm{CO}_{2}$ concentration $\left(C_{\mathrm{a}}\right)$ on iWUE and $C_{\mathrm{i}}$, it is first necessary to estimate and then remove the influences of climate variation from the isotope records (Supplementary Tables 1 and 2 and Supplementary Fig. 3).

Assessment of the climatic controls on $C_{\mathrm{i}}$ time series was performed using various climatic parameters (for example, maximum and mean monthly temperatures, monthly precipitation, vapour pressure deficit) from the points in gridded data sets closest to the individual sites based on high-frequency agreement. $C_{\mathrm{i}}$ time series were then adjusted by adding a time-varying $\mathrm{CO}_{2}$ component that is a linear function of atmospheric $\mathrm{CO}_{2}$ concentration above a pre-industrial baseline $\left(C_{\mathrm{i}}+\tau \times\left(\mathrm{C}_{\mathrm{a}}-280\right)\right)$. See Supplementary Fig. 5 for an example of these calculations. The use of the control parameter, $\tau$, allowed us determine to what extent the trends in $C_{\mathrm{i}}$ were explained by the unfiltered climatic data, and hence determine the residual long-term component indicative of a physiological response to $\mathrm{CO}_{2}$ only (Supplementary Figs 6,7 and 18 ). A $\tau$ value of zero means that the plants have maintained a constant $C_{\mathrm{i}}$ (after removal of climatic effects, denoted ${ }^{c c} C_{\mathrm{i}}$ ) and a $\tau$ value of unity means that, for every ppmv increase in $C_{\mathrm{a}}$, the ${ }^{c c} C_{\mathrm{i}}$ increases by the same amount (that is, maintenance of a constant $C_{\mathrm{a}}-C_{\mathrm{i}}$ difference). Thus, $\tau$ allows us to assess various hypotheses for the strength of plant physiological responses to $\mathrm{CO}_{2}$ (see main text). See Supplementary Methods for a more detailed description of these methods.

Dynamic global vegetation model simulations. Factorial simulations with an ensemble of DGVMs incorporating or excluding contemporary climatic and $\mathrm{CO}_{2}$ forcing data were performed to quantify water-use efficiency and transpiration responses to $\mathrm{CO}_{2}$ and climate variation for the primary PFTs relevant to the European forested region. Model analysis is an offshoot of the TRENDY Intermodel Comparison ('Trends in net land-atmosphere carbon exchange over the period 1990-2009') that was launched to provide bottom-up estimates of carbon cycle processes for the regional synthesis of the REgional Carbon Cycle Assessment and Processes (RECCAP). Six modelling teams participated (Supplementary Table 3) in our study by following a strict modelling protocol that outlined simulations for three factorial experiments (denoted S1, S2, S3) using observed climate, $\mathrm{CO}_{2}$, and land-use and land-cover change over the period 1901-2009 to drive the DGVMs. Our analysis uses model data from the 'S2' storyline that includes time-varying atmospheric $\mathrm{CO}_{2}$ concentrations and climateand time-invariant land use for 2005. We refer to this set of simulations as the 'dynamic climate, dynamic $\mathrm{CO}_{2}$ ', as both factors followed their historical courses. A fourth experiment (S4) designed especially to evaluate trends in water-use efficiency (Supplementary Figs 8-11 and 13) for this work was performed to isolate the effects of $\mathrm{CO}_{2}$ on plant physiology (Supplementary Figs 12 and 14), control simulations using historical climate but time-invariant $\mathrm{CO}_{2}$ concentrations fixed at pre-industrial levels ( $287.14 \mathrm{ppm}$; 'dynamic climate, fixed $\mathrm{CO}_{2}$ '). The standardized difference between the 'dynamic climate, dynamic $\mathrm{CO}_{2}$ ' and 'dynamic climate, fixed $\mathrm{CO}_{2}$ ' simulations (as anomalies relative to the 1901-1910 period) were used to isolate the effect of $\mathrm{CO}_{2}$ on changes in WUE metrics in the model simulations (for example, as plotted in Fig. 3a). Model differences are assumed to provide an estimate for the $\mathrm{CO}_{2}$-only effect. The DGVM simulations were also used to provide assessments for transpiration fluxes for the individual plant functional types over the twentieth century (Supplementary Figs 15-17). See Supplementary Methods for a more detailed description of the individual models, the forcing data sets, and calculation of various WUE metrics from the simulations. 